\title{
Avaliação fitoquímica e toxicológica dos extratos do fruto de Buchenavia sp.
}

\author{
Marcos Daniel de Sousa Ferreira ${ }^{a^{*}}$, Emanuelle Karine Frota Batistaa, Ingrid dos Santos Farias ${ }^{\mathrm{b}}$, Lildes \\ Ferreira Santos ${ }^{c}$, Jamylla Mirck Guerra de Oliveirad, Silvana Maria Medeiros de Sousa Silva ${ }^{a}$ \\ a Programa de Pós-Graduação em Ciência Animal - UFPI, Teresina, Piauí, 64049-550, Brasil. *marcos_daniel_pi@hotmail.com \\ ${ }^{b}$ Centro de Ciências Agrárias, Universidade Federal do Piauí Teresina, Piauí, 64049-550, Brasil. \\ ${ }^{c}$ Centro de Ciências e da Natureza, Teresina, Piauí, 64049-550, Brasil. \\ d Universidade Federal do Piauí, Teresina, Piauí, 64049-550, Brasil.
}

Recebido: 26 março 2017 / Aceito: 16 abril 2017 / Publicado online: 23 maio 2017

\begin{abstract}
Resumo
O gênero Buchenavia, conhecido popularmente como mirindiba, é endêmico e nativo do Brasil, encontrado nos cerrados e mata latifoliada, citada nos estados do Piauí e Tocantins como tóxica para animais de produção. Esta pesquisa teve como objetivo analisar qualitativamente a composição fitoquímica do extrato etanólico e frações acetato de etila e aquosa, realizar a avaliação in vitro da atividade citotóxica do extrato etanólico frente ao microcrustáceo Artemia salina e avaliar a toxicidade aguda em ratos das frações acetato de etila e aquosa dos frutos de Buchenavia sp. Foram realizadas analises fitoquímicas do extrato etanólico de Buchenavia sp e suas frações acetato de etila e aquosa. O seu potencial toxico foi avaliado frente a A. salina, nas concentrações de $0,1,10,100 \mathrm{e} 1000 \mu \mathrm{g} \mathrm{mL}^{-1} \mathrm{e}$ a toxicidade aguda em ratos foram avaliados na dosagem de $5000 \mu \mathrm{g} \mathrm{mL} \mathrm{m}^{-1}$. O extrato etanólico dos frutos de Buchenavia sp. apresenta fenóis simples, leucoantocianidinas, flavanonas e triterpenos pentacíclicos. Foi verificada ação toxica do extrato etanólico do fruto de Buchenavia sp. na concentração $1000 \mu \mathrm{g} / \mathrm{mL}$. As frações acetato de etila e aquosa não apresentam manifestações clínicas de toxicidade aguda. No entanto, uma possível toxicidade desencadeada pelo consumo desta planta não pode ser descartada.
\end{abstract}

Palavras-chave: Artemia salina, citotoxicidade, mirindiba, planta tóxica

\section{Phytochemical and toxicological evaluation of extracts of Buchenavia sp. fruit}

\begin{abstract}
The genus Buchenavia, popularly known as Mirindiba, is endemic and native to Brazil, found in the cerrado and kills of broadleaf, cited in the states of Piauí and Tocantins as toxic for production animals. The objective of this research was to qualitatively analyze the phytochemical composition of the ethanolic extract and ethyl acetate and aqueous fractions, to carry out the in vitro evaluation of the cytotoxic activity of the ethanol extract against the microcrustacean A. salina and to evaluate the acute toxicity in rats of the fractions ethyl acetate And aqueous solution of the fruits of Buchenavia sp. Phytochemical analyzes of the ethanolic extract of Buchenavia sp and its ethyl acetate and aqueous fractions were performed. Its toxic potential was evaluated against A. salina at concentrations of $0.1,10,100$ and $1000 \mu \mathrm{g} \mathrm{mL}-1$ and the acute toxicity in rats was evaluated at the dosage of $5000 \mu \mathrm{g} \mathrm{mL}-1$. The ethanolic extract of the fruits of Buchenavia sp. Presents simple phenols, leucoanthocyanidins, flavanones and pentacyclic triterpenes. It was verified toxic action of the ethanolic extract of the fruit of Buchenavia sp. At the concentration $1000 \mu \mathrm{g} / \mathrm{ml}$. The ethyl acetate and aqueous fractions do not present clinical manifestations of acute toxicity. However, a possible toxicity triggered by the consumption of this plant cannot be ruled out.
\end{abstract}

Keywords: Artemia salina, cytotoxicity, mirindiba, toxic plant.

\section{Introdução}

A Buchenavia sp., pertencente ao gênero Buchenavia (Eichler 1866), encontrada no cerrado e mata latifoliada, popularmente conhecida por mirindiba, cuiarana e pebanheira, é uma espécie arbórea com altura entre 5 e $15 \mathrm{~m}$, copa ampla, densa e diâmetro do tronco entre 30 a $50 \mathrm{~cm}$, com floração de agosto-setembro e frutificação setembro-outubro
(Lorenzi, 2002). Como os frutos são muito palatáveis os animais se alimentam avidamente, e a quantidade de frutos produzidos varia a cada ano, se em um ano a planta produz mais, no ano seguinte a produção é menor (Mello et al., 2010).

Há poucos relatos científicos acerca do fruto do gênero Buchenavia sp. encontrado no Piauí. Estes referem-se ao extrato etanólico oriundo da casca da árvore, onde observou- 
se, por meio de prospecção fitoquímica, a presença de compostos fenólicos simples, flavonóis, leucoantocianidinas, esteróides e triterpenos pentacíclicos livres como componentes majoritários (Ferreira et al., 2016).

Levantamentos realizados por Costa (2009) e Mello et al. (2010), demonstraram que a espécie Buchenavia tomentosa Eichler (mirindiba) é citada como tóxica para a reprodução em animais de produção, mas sem comprovação científica.

Várias são as possibilidades de se realizar o estudo toxicológico de plantas, e assim comprovar sua possível ação tóxica, pois para uma substância ser considerada um agente tóxico dependerá das condições de exposição, tais como: dose, tempo, frequência e via de administração (Venancio, 2006). A toxicidade aguda e crônica de substâncias pode ser avaliada por meio de observações do comportamento, variações no consumo de ração, evolução ponderal, avaliação biométrica dos órgãos e alterações orgânicas visualizáveis macro e microscopicamente. As determinações hematológicas e bioquímicas sanguíneas são fundamentais para predizer a influência da substância-teste sobre a homeostase e o estado das funções hepática e renal (OECD, 2008).

Ensaios de letalidade em organismos simples estão entre os mais empregados na toxicologia como estudo preliminar de substâncias, sendo muito utilizados o bioensaio com microcrustáceo marinho A. salina Leach (Grinevicius, 2006). Este ensaio de letalidade permite a avaliação da toxicidade geral, sendo considerado essencial como bioensaio preliminar no estudo de compostos com potencial atividade biológica (Parra et al., 2001).

Esta pesquisa objetivou analisar qualitativamente a composição fitoquímica do extrato etanólico e frações acetato de etila e aquosa, realizar a avaliação in vitro da atividade citotóxica do extrato etanólico frente ao microcrustáceo $A$. salina e avaliar a toxicidade aguda em ratos das frações acetato de etila e aquosa dos frutos de Buchenavia sp.

\section{Material e Métodos}

Os ensaios toxicológicos foram conduzidos no Biotério de Manutenção de Animais Destinados à Experimentação (BIOMADEX) e Laboratório de Ciências Fisiológicas do Centro de Ciências Agrárias (CCA) da Universidade Federal do Piauí (UFPI).

\section{Preparação do extrato}

A amostra vegetal da planta Buchenavia sp foi coletada no município de Floriano, Estado do Piauí e transportada para Teresina, sendo registrada e armazenada no Herbário Graziela Barroso da UFPI sob o registro TEPB 27.957. Seus frutos foram processados e submetidos à maceração a frio com etanol (99,6 PA), durante 5 dias à temperatura ambiente e ao abrigo da luz, realizando-se quatro extrações sucessivas. Após a filtração, foi concentrado em evaporador rotativo a $40{ }^{\circ} \mathrm{C}$, depois foi liofilizado, acondicionado em frascos de vidro âmbar e conservado em geladeira $\left(15^{\circ} \mathrm{C}\right)$.

Foram utilizados ratos Wistar (Rattus norvergicus albinus, Berkenhout) do BIOMADEX/CCA/UFPI, mantidos em ambiente com temperatura controlada $\left(23 \pm 1{ }^{\circ} \mathrm{C}\right)$, com

\section{Fracionamento do extrato etanólico}

O extrato etanólico bruto foi suspenso em mistura de metanol $(\mathrm{MeOH})$ e água (1:2) obtendo-se um volume de 1500 $\mathrm{mL}$ e submetido a uma partição líquido-líquido com acetato de etila (AcOEt) (32 x $200 \mathrm{~mL})$ sucessivamente, fornecendo as frações acetato de etila $(50 \mathrm{~g}, 27 \%)$ e aquosa $(120 \mathrm{~g}, 65 \%)$.

\section{Protocolo: Testes fitoquímicos}

Os testes qualitativos para detecção dos constituintes do metabolismo secundário foram realizados segundo adaptações de Matos, (2009) e Costa et al., (2011). Pesou-se 1,00 g do extrato etanólico e das frações de AcOEt e aquosa dos frutos de Buchenavia sp., que foi solubilizada em uma mistura de EtOH/H20 (8:2) obtendo-se um volume de $100 \mathrm{~mL}$. A solução hidroalcoólica do extrato e das frações foi utilizada nos testes fitoquímicos para a análise dos seguintes constituintes: fenóis, taninos, antocianinas, antocianidinas, flavonoides, leucocianidinas, catequinas, flavonas, flavonóis, flavononas, flavononóis, xantonas, diidroflavonóis, esteroides, triterpenos, saponinas e alcaloides.

\section{Protocolo 2: Bioensaio frente a Artemia salina}

$\mathrm{O}$ bioensaio de toxicidade frente à $A$. salina foi realizado segundo a metodologia proposta por Meyer et al. (1982) com algumas adaptações. Neste ensaio foram utilizados Cistos do microcrustáceo A. salina obtidos em lojas especializadas de aquário marinho no município de Teresina, Piauí. Para obtenção das condições desejadas à eclosão dos ovos de $A$. salina, a água do mar artificial foi preparada com os seguintes reagentes: água destilada, Cloreto de Sódio $\left(35 \mathrm{~g} \mathrm{~L}^{-1}\right)$ e Bicarbonato de Sódio $\left(6,5 \mathrm{~g} \mathrm{~L}^{-1}\right)$. Esta água artificial foi aerada durante 30 minutos em artemeira (Meyer et al., 1982).

Foram incubados $100 \mathrm{mg}$ de cistos de A. salina por 48 horas. Durante esse período a $A$. salina foi mantida em uma caixa térmica com iluminação de 9 watts. A cultura foi mantida sob aeração e agitação constantes, em uma temperatura de $28 \pm 2{ }^{\circ} \mathrm{C}$.

Foram transferidas 10 larvas para cada tubo de ensaio e o volume foi então completado para $9 \mathrm{~mL}$ da solução água do mar artificial, sendo adicionado $1 \mathrm{~mL}$ do extrato etanólico de Buchenavia sp. nas concentrações: $1,10,100$ e $1000 \mu \mathrm{g} \mathrm{mL}^{-1}$. $\mathrm{O}$ teste foi realizado em triplicata para cada concentração do extrato em estudo. Para o controle negativo foi adicionado apenas 10 larvas em $10 \mathrm{~mL}$ de água salina, totalizando 15 tubos. Os náuplios de $A$. salina foram incubados por 24 horas sob iluminação artificial (9 Watts) numa temperatura de $28 \pm 2$ ${ }^{\circ} \mathrm{C}$. Decorrido este período, os sobreviventes foram contados com o auxílio de uma lupa. Foram consideradas larvas mortas todas que não apresentavam qualquer movimento ativo em cerca de vinte segundos de observação.

\section{Protocolo 3: Toxicidade Aguda em ratos}

iluminação artificial (15 watts) obedecendo a um fotoperíodo de 12 horas, com livre acesso a água e ração. O protocolo experimental foi aprovado pelo Comitê de Ética em 
Experimentação Animal da UFPI, com parecer n ${ }^{\circ}$ 049/12.

Nesse estudo, foram adotadas metodologias preconizadas pela OECD, utilizando a dose mais alta (5000 mg kg-1) recomendada para substâncias não testadas ou com histórico de Toxicidade Desconhecida (OECD, 2008). Como não foram observados óbitos, esta foi a única dose utilizada no experimento.

Foram utilizados 18 ratos $(\mathrm{n}=6$, machos e fêmeas) para cada um dos grupos tratados (Frações AcOEt 5000mg kg-1 e Aquosa $5000 \mathrm{mg} \mathrm{kg}^{-1}$, por via oral) e controle (água destilada $10 \mathrm{~mL} / \mathrm{kg}$, via oral). Após a administração, os animais foram avaliados nos seguintes períodos de tempo: $30 \mathrm{~min} ., 1 \mathrm{~h}, 2 \mathrm{~h}$, $4 \mathrm{~h}$ e $24 \mathrm{~h}$, e depois, diariamente, até o $14^{\circ}$ dia após o tratamento, para a observação do aparecimento dos seguintes sinais: hiperatividade, tremores, convulsão, piloereção, hipnose, sedação, resposta ao toque, reflexo auricular, limpeza, levantar, escalar, vocalizar, força para agarrar, salivação, cianose e morte, seguindo o screnning hipocrático. Os sinais avaliados na observação comportamental seguiram o protocolo segundo Malone e Robichaud (1962) e Malone (1977). Os animais foram pesados diariamente, durante 14 dias de tratamento, para observar alterações de peso e também foram pesadas a ração e quantidade de água ingerida pelos animais.

Ao fim desse experimento, os animais foram anestesiados por associação anestésica ( $80 \mathrm{mg} \mathrm{Kg}^{-1}$ ketamina $+8 \mathrm{mg} \mathrm{Kg}^{-1}$ xilazina) para coleta de sangue, e em seguida, eutanasiados por sobredose desta mesma associação para coleta e mensuração de órgãos: fígado, baço, rins, coração, pulmão, estomago e intestinos delgado e grosso. Os órgãos coletados foram seccionados e fixados em formalina tamponada, submetidas ao processamento histológico, seccionados em micrótomo, na espessura de 5,0 $\mu \mathrm{M}$ e submetidos à coloração com hematoxilina-eosina (Bacha; Wood, 1990).

\section{Análise Estatística}

Os resultados foram expressos por média \pm erro padrão. Os resultados obtidos foram submetidos à análise de variância a $5 \%$ de probabilidade (ANOVA) e quando identificada diferença estatística, foi aplicado o teste de Tukey $(\mathrm{p}<0,05)$. Foi utilizado o programa GraphPad Prism versão 5.0. A Concentração Letal Média (CL50) do Extrato foi determinada por análise de regressão.

\section{Resultados e Discussão}

O extrato etanólico dos frutos de Buchenavia sp., e as frações obtidas da sua partição líquido-líquido (Frações AcOEt e Aquosa) apresentaram resultado positivo para diversas classes de metabólitos secundários (Tabela 1). Após a revelação das cromatoplacas do extrato etanólico dos frutos de Buchenavia sp. e suas frações, observou-se a presença da cor amarela, característica de compostos fenólicos e da coloração roxa característica de compostos terpênicos.

Em Buchenavia sp., os metabólitos secundários predominantes no extrato etanólico bruto e suas frações foram os fenóis simples, leucoantocianidinas, flavanonas e triterpenos pentacíclicos. Resultado similar foi reportado em estudo de prospecção fitoquímica do extrato etanólico da casca de Buchenavia sp., em que os constituintes majoritários foram os fenóis simples, flavonóis, esteróides, leucoantocianidinas e triterpenos pentacíclicos livres (Ferreira et al., 2016).

Tabela 1. Resultados da abordagem fitoquímica do extrato bruto, etanólico do fruto de Buchenavia sp.

\begin{tabular}{lccc}
\hline \multirow{2}{*}{ Classe de metabólito } & \multirow{2}{*}{$\begin{array}{c}\text { Extrato } \\
\text { bruto }\end{array}$} & $\begin{array}{c}\text { Acetato } \\
\text { de etila }\end{array}$ \\
\cline { 3 - 5 } Fenóis Simples & ++ & + & + \\
Taninos Hidrolisáveis & + & ++ & + \\
Taninos Catéquicos & - & - & - \\
Antocianinas & - & - & - \\
Antocianidinas & - & - & - \\
Leucoantocianidinas & +++ & ++ & + \\
Catequinas & + & - & - \\
Flavonas & + & - & + \\
Flavonóis & + & - & + \\
Flavanonas & ++ & ++ & ++ \\
Flavanonóis & + & - & + \\
Xantonas & + & - & + \\
Chalconas E Auronas & - & - & - \\
Diidroflavonóis & - & - & - \\
Esteróides & - & - & - \\
Triterpenos Pentacíclicos & +++ & + & - \\
Heterosídeos Saponínicos & + & + & ++ \\
Alcalóides & - & - & - \\
\hline Forte: (+++); Médio: $(++) ;$ Fraco: $(+) ;$ Ausente: & $(-)$ &
\end{tabular}

Forte: (+++); Médio: (++); Fraco: (+); Ausente: (-).

Plantas consideradas tóxicas produzem metabólitos secundários que pela inalação, ingestão ou contato podem causar alterações patológicas em homens e animais e, em alguns casos, pode levar a sérios distúrbios no organismo e até mesmo óbito (Vasconcelos et al., 2009; Jesus e Suchara, 2013).

Estudo realizado com o extrato metanólico da espécie $B$. tetraphylla (Aubl.) revelou a presença de compostos, tais como flavonóides e taninos (Violante et al., 2009). Em estudos realizados com outras espécies de combretáceas, como Terminalia fagifolia (Mart. et Zucc), Combretum laxum (Jacq), T. glabrescens (Mart) $e$ T. argentea (Mart) verificouse que as plantas deste gênero são conhecidas pela ocorrência dos metabólitos secundários: triterpenos pentacíclicos e seus derivados glicosilados, flavonoides, taninos e outros compostos aromáticos (Garcez et al, 2016). Estes achados sugerem a necessidade de estudos posteriores a fim de melhor caracterizar as substâncias presentes nos frutos de Buchenavia sp.

Alguns dos constituintes fitoquímicos encontrados neste estudo foram isolados de outras espécies pertencentes à família Buchenavia sp., como a espécie B. oxicarpa (Mart.), na qual foram encontrados taninos e terpenos e a espécie Combretum fragans (F. Hoffm), onde identificou-se a presença de taninos, flavonoides e saponinas (Hernes et al., 2004; Batawila et al., 2005). Triterpenóides foram isolados das folhas de $C$. collinum (Fresen) e triterpenos lupenona, lupeol e ácido betulínico nas raízes e frutos de $C$. mellifluum (Eichler) (Rogers et al., 1999; Rocha et al., 2007). Flavonóides 
e flavonas foram isolados de sementes de B. capitata (Vahl) Eichler (Houghton, 2002).

Sabe-se que muitas substâncias pertencentes a estes grupamentos químicos possuem efeitos tóxicos sobre o sistema reprodutivo de mamíferos e variados efeitos farmacológicos (Falodun et al., 2005).

As saponinas, presentes no extrato do presente estudo, apresentam uma variedade de propriedades biológicas devido a sua capacidade de formar complexos com esteroides, proteínas e fosfolipídeos de membranas, podendo apresentar atividade hemolítica, anti-helmíntica, hipocolerestomiante, anti-inflamatória, anti-viral, moluscicida e espermicida (Simões et al., 2010).

Com a proposta de verificar a toxicidade de novos compostos bioativos vários ensaios são utilizados, como o ensaio de letalidade com o microcrustáceo A. salina, que foi desenvolvido para detectar compostos ativos em extratos vegetais (Silva et al., 2005), mas que pode ser utilizado para expressar a toxicidade de um extrato (Lima et al., 2002).

O extrato do fruto de Buchenavia sp. aqui investigado, reporta indícios de toxicidade na concentração de $1000 \mu \mathrm{g} \mathrm{mL}$ ${ }^{1}$ por ser capaz de causar a morte de $49,63 \%$ de larvas de $A$. salina durante as primeiras 24 horas de exposição (Tabela 2 ).

Tabela 2. Mortalidade média (\%) de náuplios Artemia salina de acordo com a concentração $\left(\mu \mathrm{g} \mathrm{mL}^{-1}\right)$ do extrato etanólico de Buchenavia sp.

\begin{tabular}{lcc}
\multicolumn{1}{c}{ Concentração } & Média $(\%)$ & Erro Padrão $( \pm)$ \\
0,0 (controle) & $10,88^{\mathrm{b}}$ & 5,50 \\
1,0 & $17,37^{\mathrm{b}}$ & 4,07 \\
10,0 & $18,70^{\mathrm{b}}$ & 4,06 \\
100,0 & $16,09^{\mathrm{b}}$ & 3,15 \\
1000,0 & $49,63^{\mathrm{a}}$ & 13,84 \\
\hline
\end{tabular}

Valor médio com letra diferente indica variação estatisticamente significativa em relação aos demais valores para o teste ANOVA, seguido pelo teste de Tukey $(\mathrm{p}<0,05)$ para comparação de médias.

Com os dados de mortalidade obtidos, determinou-se a CL50, isto é, a concentração que causa mortalidade em $50 \%$ dos organismos durante o período observado. $\mathrm{O}$ extrato etanólico do fruto de Buchenavia sp. foi testado nas concentrações de $1,10,100$ e $1000 \mu \mathrm{g} \mathrm{mL}^{-1}$ e controle negativo com solução salina. A análise do ensaio testado conferiu para o CL50 para o extrato etanólico do fruto de Buchenavia sp. foi a partir de $37,29 \mu \mathrm{g} \mathrm{mL}^{-1}$.

De acordo com Nguta et al. (2011), tanto extratos orgânicos, quanto extratos aquosos com valores de CL50 menores que $100 \mu \mathrm{g} \mathrm{mL}^{-1}$ apresentam alta toxicidade. Sendo assim, o extrato etanólico do fruto de Buchenavia sp. mostrou, no presente ensaio, atividade tóxica frente o microcrustáceo A. salina.

Pereira et al. (2014) demonstraram a toxicidade do extrato de Myracrodruon urundeuva nas concentrações de 100 e 1000 $\mu \mathrm{g} \mathrm{mL}^{-1}$, sendo este capaz de causar a morte de mais de $70 \%$ de larvas de A. salina, resultado semelhante foi observado por Amaral e Silva (2008) ao estudar o extrato de Anadenanthera falcata que demonstrou toxicidade alta nas maiores concentrações $\left(1000,500\right.$ e $\left.250 \mu \mathrm{g} \mathrm{mL}^{-1}\right)$.

Em estudos, Meyer et al. (1982), estabeleceram uma 20 relação entre o grau de toxicidade e a dose letal média, CL50, apresentada por extratos de plantas sobre larvas de A. salina, e desde então, considera-se que quando são verificados valores acima $1000 \mu \mathrm{g} \mathrm{mL}^{-1}$, estes, são considerados atóxicos.

A avaliação da toxicidade aguda é uma metodologia empregada para verificar e classificar as substâncias quanto a sua capacidade de provocar danos agudos em organismos vivos. É considerado um ensaio essencial para o estabelecimento de doses a serem utilizadas em estudos subcrônicos (Bighetti et al., 2004).

Estes estudos demonstram que toda substância é um agente tóxico em potencial, dependendo apenas das condições de exposição como: dose, tempo, frequência e via de administração (Valadares, 2006; Zatta et al., 2009; Pires Júnior et al., 2012).

$\mathrm{Na}$ avaliação aguda das frações acetato de etila e aquosa do extrato etanólico do fruto de Buchenavia sp., não foi observada morte nem qualquer sinal de toxicidade nos animais controle e tratados durante todo o estudo. $\mathrm{Na}$ avaliação até o $14^{\circ}$ dia, não se observou diferenças quanto ao ganho de peso, bem como quanto ao consumo de água e ração entre os dois grupos tratados e o grupo controle. No screening hipocrático, nenhuma alteração sensorial e/ou motora foi observada entre os grupos.

Esses dados corroboram com Ferreira et al. (2016) que utilizou o extrato etanólico da casca do fruto de Buchenavia sp., em camundongos na posologia de $5 \mathrm{~g} / \mathrm{kg}$ por via oral onde os animais não apresentaram nenhuma alteração clínica nas primeiras 24 horas do experimento, sendo esta dose considerada inócua quanto a incidência de óbitos pela via oral, e muito segura, segundo os padrões da Organização para Cooperação Econômica e Desenvolvimento (Organization for Economic Cooperation and Developmant - OECD).

A ação tóxica de uma substância pode comprometer alguns órgãos, tais como fígado, baço e rins. Podem induzir alterações morfológicas mais ou menos características, sendo o exame histológico um meio complementar muito útil na confirmação diagnóstica (Tokarnia et al., 2012).

Quanto à massa dos órgãos não se observou diferença significativa entre os grupos tratados em relação ao grupo controle para coração, fígado, pulmão, baço, rins, estômago, intestino delgado e grosso (Tabela 3). Microscopicamente não foi observado alterações na histologia dos órgãos desses animais.

Observando os parâmetros bioquímicos de ratos tratados com as frações acetato de etila e aquosa do extrato etanólico do fruto de Buchenavia sp. e controle, no estudo de toxicidade aguda, com uma única dose, verificou-se que não houve diferença estatística nestes parâmetros obtidos por meio da análise do soro sanguíneo destes animais (Tabela 4).

Esses danos observados podem ter alguma relação com as condições alimentares ou alguma manifestação sofrida por parte dos animais, visto que lesões leves foram observadas nos grupos tratados com as frações do extrato e no controle. Além disso, a não ocorrência de alterações nos testes bioquímicos realizados, e a não observação de alterações no comportamento indicativos de toxicidade, corroboraram para considerar as frações do extrato analisadas como destituídas de toxicidade aguda para os ratos. 
Tabela 3. Massa dos órgãos de ratos tratados com as frações acetato de etila e aquosa do extrato etanólico (5.000 $\mathrm{mg} \mathrm{Kg}{ }^{-1}$ ) do fruto de Buchenavia sp.

\begin{tabular}{lccc}
\hline \multirow{2}{*}{ Variáveis } & \multicolumn{3}{c}{ Peso $(\mathrm{g})$} \\
\cline { 2 - 4 } & Controle & $\begin{array}{c}\text { Acetato de } \\
\text { etila }\end{array}$ & Aquosa \\
\hline Pulmão & $2,97 \pm 1,91$ & $1,80 \pm 0,10$ & $1,55 \pm 0,33$ \\
Coração & $1,06 \pm 0,13$ & $0,98 \pm 0,04$ & $0,95 \pm 0,10$ \\
Fígado & $11,41 \pm 1,62$ & $10,82 \pm 1,46$ & $11,01 \pm 1,71$ \\
Baço & $0,78 \pm 0,14$ & $0,59 \pm 0,25$ & $0,58 \pm 0,21$ \\
Rim direito & $1,09 \pm 0,10$ & $0,97 \pm 0,16$ & $0,96 \pm 0,16$ \\
Rim esquerdo & $1,09 \pm 0,12$ & $0,93 \pm 0,10$ & $0,92 \pm 0,17$ \\
Estomago & $3,38 \pm 1,04$ & $5,54 \pm 1,80$ & $3,13 \pm 1,70$ \\
Intestino delgado & $10,67 \pm 1,35$ & $8,32 \pm 2,23$ & $7,80 \pm 2,40$ \\
Intestino grosso & $10,91 \pm 1,17$ & $9,98 \pm 2,15$ & $9,27 \pm 1,46$ \\
\hline
\end{tabular}

Os resultados foram expressos em média \pm erro padrão da média para cada órgão analisado. Foi realizado ANOVA seguido pelo teste de Tukey ( $\mathrm{p}<$ $0,05)$.

Tabela 4. Parâmetros bioquímicos de ratos tratados com as frações acetato de etila e aquosa do extrato etanólico (5.000 $\mathrm{mg} / \mathrm{Kg}$ ) do fruto de Buchenavia sp. em dose única.

\begin{tabular}{lccc}
\hline \multirow{2}{*}{$\begin{array}{c}\text { Parâmetro } \\
\text { bioquímico }\end{array}$} & Controle & $\begin{array}{c}\text { Acetato de } \\
\text { etila }\end{array}$ & Aquosa \\
\cline { 2 - 4 } & & $67,27 \pm 1,62$ & $66,90 \pm 0,44$ \\
Uréia & $69,29 \pm 28,17$ & $0,41 \pm 0,12$ & $0,49 \pm 0,05$ \\
Creatinina & $0,56 \pm 0,07$ & 0,05 & \\
ALT & $111,20 \pm 77,22$ & $78,97 \pm 8,40$ & $69,33 \pm 19,12$ \\
AST & $234,30 \pm 73,9$ & $145,7 \pm 30,76$ & $133,2 \pm 31,9$ \\
\hline
\end{tabular}

Uréia e creatinina em $\mathrm{mg} \mathrm{dL}^{-1}$; ALT e AST em $\mathrm{UL}^{-1}$. Os resultados foram

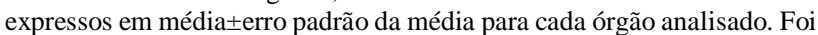
realizado ANOVA seguido pelo teste de Tukey ( $\mathrm{p}<0,05)$. ALT: alanina aminotransferase; AST: aspartato aminotransferase.

O fígado é bastante suscetível à ação de compostos químicos, pelo fato de substâncias administradas por via oral sofrerem absorção gastrintestinal e poderem ser transportadas primeiramente para o fígado (veia porta hepática). Assim sendo, um agente tóxico vai primeiramente para o fígado para ser distribuído na corrente sanguínea (Túrmina, 2012). Os rins têm como função depurar o sangue, regular a pressão sanguínea e os volumes do fluido corporal. Além disso, atuam na manutenção do equilíbrio ácido-básico e na formação e liberação de hormônios (Gartner e Hiatt, 2010). Vários fatores podem influenciar na sensibilidade renal a substâncias consideradas tóxicas, como o fluxo arterial renal, e o aumento na concentração dos produtos de excreção após a reabsorção de água no líquido tubular, como consequência, dessa concentração do líquido tubular, após a remoção de água e sais, concentram todos os produtos químicos nele contidos, assim, uma concentração não tóxica no plasma pode ser convertida para tóxica no fluido tubular, prejudicando o funcionamento do órgão (Middendorf e Williams, 2000; Hodgson e Levi, 2004).

\section{Conclusão}

O extrato etanólico dos frutos de Buchenavia sp. apresenta como principais constituintes as seguintes classes de compostos: fenóis simples, leucoantocianidinas, flavanonas e triterpenos pentacíclicos. Este extrato possui atividade biológica frente ao microcrustáceo A. salina, apresentando indícios de toxicidade. As frações acetato de etila e aquosa obtidas do extrato etanólico do fruto de Buchenavia sp., não apresenta manifestações clínicas de toxicidade aguda, levando-se em considerações a inexistência de diferenças comportamentais entre os grupos, a ausência de alterações no perfil bioquímico e ausência de óbito. É importante ressaltar que uma possível toxicidade desencadeada após a ingestão desta planta em ruminantes não pode ser descartada pelas diferenças entre esta espécie e a espécie utilizada neste estudo.

\section{Referências}

Amaral, E.A.; Silva, R.M.G. 2008. Avaliação da toxicidade aguda de angico (Anadenanthera falcata), pau santo (Kilmeyera coreacea), aroeira (Myracrodruon urundeuva) e cipó de são João (Pyrostegia venusta), por meio do bioensaio com Artemia salina. Revista Eletrônica da Pesquisa, 5(5): $1-16$

Bacha, W. J.; Wood, L. M. Colors atlas of veterinary histology. Philadelphia: Lea and Febiger, Philadelphia. 1990. 269p.

Bighetti, A.E.; Antônio, M.A.; Possenti, A. Foglio, M.A.; Siqueira, M.G.; Carvalho, J.E. 2004. Efeitos da administração aguda e subcrônica da Luehea divaricata Martus et Zuccarini. Lecta, 22(1/2): 53-58.

Batawila, K.; Kokou, K.; Koumaglo, K. Gbéassor, M.; Foucault, B.; Bouchet, P.; Akpagana, K. 2005. Antifungal activities of five Combretaceae used in Togolese traditional medicine. Fitoterapia, 76(2), 264-268.

Bianchi, M.L.P.; Antunes, L.M.G. 1999. Radicais livres e os principais antioxidantes da dieta. Revista de Nutrição, 12(2): 123-130.

CFMV. Conselho Federal de Medicina Veterinária. Resolução no 1000 de $11 / 05 / 2012$.

Chhabra, S.C.; Mahunnah, B.L.A.; Mshiu, E.N. 1987. Plants used in traditional medicine in eastern Tanzania. I. Pteridophytes and angiosperms (Acanthaceae to Canellaceae). Journal of Ethnopharmacology, 21(3): 253-277.

Costa, A.C.R.; Silva, A.L.R.; Sousa, C.R. 2011. Abordagem fitoquímica, ação inibitória de acetilcolinesterase e atividade nematicida de Astronium fraxinifolium Schott. Quimica no Brasil, 5: 27-34.

Costa, A.M.D. 2009. Plantas toxicas de interesse agropecuário nas microrregiões de Araguaina e Bico do Papagaio, Norte do Tocantins. Dissertação de Mestrado, Universidade Federal do Tocantins, Palmas, $104 \mathrm{f}$.

Falodun, A.; Usifoh, C.O.; Nworgu, Z.A. 2005. Phytochemical and active column fractions of Pyrenacantha staudtii leaf extracts on isolated rat uterus. Pakistan journal of pharmaceutical sciences, 18(4): 31-35.

Ferreira, M.D.S.; Batista, M.C.S.; Silva, S.M.M.S. 2016. Estudo de toxicidade de planta de interesse pecuário. Estudo de toxicidade sistêmica e reprodutiva do extrato etanólico da casca de Buchenavia sp. em ratos. Editora Novas Edições Acadêmicas. 60p.

Garcez, F.R.; Garcez, W.S.; Yoshida, N.C.; Figueiredo, P.O.A. 2016. A Diversidade dos Constituintes Químicos da Flora de Mato Grosso do Sul e sua Relevância como Fonte de Substâncias Bioativas. Revista Virtual de Química, n.8(1): 97-129.

Gartner, L.P.; Hiatt, J.L. 2010. Sistema reprodutor feminino e sistema reprodutor masculino. In: Atlas colorido de histologia. 5 ed. Rio de Janeiro: Guanabara Koogan, p. 357-378.

Grinevicius, V.M.A.S. 2006. Avaliação da remediação de percolados de uma indústria têxtil utilizando bioindicadores e biomarcadores. Dissertação de Mestrado, Universidade Federal de Santa Catarina, Florianópolis, 179 f.

Hernes, P.J.; Hedges, J.I. 2004. Tannin signatures of barks, needles, leaves, cones, and wood at the molecular level. Geochimica et Cosmochimica Acta, 68(6): 1293-1307.

Hodgson, E.; Levi, P. 2004. Susceptibility of the renal system. In: Hodgson, E. A textbook of modern toxicology. 3 ed. New York: John Wiley \& Sons, p. 273-78.

Houghton, P.J.J. 2002. Chromatography of the chromone and flavonoid alkaloids. Journals Chromatogr, 967(1): 75-84.

Jesus, N.A.; Suchara, E.A. 2013. Cultivo de plantas tóxicas e a ocorrência de intoxicações em domicílios no município de Barra do Graças. Revista Eletrônica da UNIVAR, 2(10): 89-95.

Khanam, U.K.S.; Oba, S.; Yanase, E.; Murakami, Y. 2012. Phenolic acids, flavonoids and total antioxidant capacity of selected leafy vegetables. Journal Functional Foods, 4(4): 979-987.

Lima, N.M.F.; Santos, A.F.; Porfírio, Z.; Goularta, M.O.F.; Sant'Anaa, A.E.G. 2002. Toxicity of lapachol and their potassium solts against Biomphalaria 
Ferreira, et al. - Análise do fruto de Buchenavia sp.

glabrata, Schitosoma mansoni cercariae, Artemia salina and Tilapia nilotica. Acta Tropica, 83(1): 43-47.

Lorenzi, H. 2002. Árvores Brasileiras - Manual de Identificação e Cultivo de Plantas Arbóreas Nativas do Brasil. V.2. $2^{\mathrm{a}}$ ed. Editora Plantarum. Nova Odessa - SP. 368 p.

Malone, M.H. 1977. Pharmacological approaches to natural product, screening and evaluation. In: Wagner, H. \& Wolf, P. (Eds), Natural Products and Plant Drugs with Pharmacological, Biological or Therapeutical Activity., Springer-Verlag, Berlin, p.23-53.

Malone, M.H.; Robichaud. R.C. 1962. A hippocratic screening for pure or drug materials. Lloydia, 25(4): 23-53.

Martinez, M.T.S., Dieguez, T.S.; Cansino, N.S.C.; Gracia, E.A.; Sampedro, J.G. 2010. Innovacion de productos de alto valor agregado a partir de latuna mexicana. Revista Mexicana de Agronegocios, 14(27): 435-441.

Matos, F.J.A. 2009. Introdução à Fitoquímica Experimental. $3^{\mathrm{a}}$ ed. Fortaleza: UFC, 150p.

Mello, G.W.S.; Oliveira, D.M.; Carvalho, C J.S.; Pires, L.V.; Costa, F.A.L.; Riet-Correa, F.; Silva, S.M.M. 2010. Plantas tóxicas para ruminantes e equídeos no Norte Piauiense. Pesquisa Veterinária Brasileira, 30(1): 1-9.

Meyer, B.N.; Ferrigni, N.R.; Putnam, J.E.; Jacobsen, L.B.; Nichols, D.E.; McLaughlin, J.L. 1982. Brine shrimp: a convenient general bioassay for active plant constituents. Planta Medica, 45(5): 31-34

Middendorf, P.J.; Williams, P.L. 2000. Nefrotoxicity: Toxic Responses of the Kidney. In: Williams, P.L., James, R.C., Roberts, S.M. Principles of toxicology: environmental and industrial applications. A Wileyintercience publication, Second Edition. New York, cap 5. p. 120-125.

Nguta, J.M.; Mbariaa, J.M.; Gakuyab, D.W.; Gathumbic, P.K.; Kabasad, J.D.; Kiamae, S.G. 2011. Biological screening of Kenya medicinal plants using Artemia salina L. (Artemiidae). Pharmacology online, 2: 458-278.

OECD (Organisation for Economic Co-operation and Development). 2008. Guidelines for the testing of chemicals: Acute Oral Toxicity - Up-andDown- Procedure (UDP), Item 425.

Parra, A.L.; Yhebra, R. S.; Sardiñas, G.I.; Buela, I.L. 2001. Comparative study of the assay of Artemia salina L. and the estimate of the medium lethal dose (LD50 value) in mice, to determine oral acute toxicity of plant extracts. Phytomedicine, 8(5): 395-400.

Pereira, P.S.; Barros, M.L.; Brito, A.M.; Duarte, A.E.; Maia, A.J. 2014. Uso da Myracroduon urundeuva Allemão (aroeira do sertão) pelos agricultores no tratamento de doenças. Revista Cubana de Plantas Medicinales, 19(1): 51-60.

Pires Junior, H.B., Borges, L.M.F.; Sousa, L.A.D.; Cunha, L.C.; Lino Júnior, R.S.; Melo, D.F.A.; Pereira, M.E. 2012. Avaliação da toxicidade aguda do extrato hexânico de frutos de Melia azedarach (MELIACEAE) em camundongos. Ciência Animal Brasileira, 13(4): 512-519.

Rogers, C. B.; Coombes, P. H. 1999. Acidic triterpene glycosides in trachoma secretions differentiate subspecies of Combretum collinum in South Africa. Biochemical Systematics and Ecology, 27(3): 321-323.

Silva, C.A.M. 2007. Contribuição ao estudo químico e biológico de Pouteria gardnerii (Mart. \& Miq.) Baehni (Sapotaceae). Dissertação de Mestrado, Faculdade de ciências da saúde. Universidade de Brasília, Brasília. 197p.

Silva, T.M.S.; Batista, M.M.; Camara, C.A. Agra, M.F. 2005. Molluscicidal activity of some Brazilian Solanum spp. (Solanaceae) against Biomphalaria glabrata. Annals of Tropical Medicine \& Parasitology. 99(4), 419-425.

Simões, C.M.O.; Schenkel, E.P.; Gosmann, G. 2010. Farmacognosia: da planta ao medicamento. $6^{\circ}$ ed. Porto Alegre: UFSC.

Tokarnia, C.H.; Brito, M.F.; Barbosa, J.D. 2012. Plantas tóxicas do Brasil para animais de produção. 2.ed. Rio de Janeiro: Helianthus, 566p.

Túrmina, J.A. 2012. Avaliação da toxicidade subcrônica in vivo do exopolissacarídeo produzido pelo fungo Lasiodiplodia theobromae MMPI. Dissertação de mestrado, Universidade Estadual do Centro-oeste. $50 f$.

Valadares, M. C. 2006. Avaliação de toxicidade aguda: estratégias após a "era do teste DL50". Revista Eletrônica de Farmácia, 3(2): 93-98.

Vasconcelos, J.; Vieira, J.G.P.; Vieira, E.P.P. 2009. Plantas Tóxicas: Conhecer para Prevenir. Revista Científica da UFPA, 7(1): 1-10.

Venancio, A.M. 2006. Toxicidade aguda e atividade antinociceptiva do óleo essencial do Ocimum basilicum L. (manjericão), em Mus músculos (camundongos). Dissertação de Mestrado, Universidade Federal de Sergipe, Aracaju. $110 \mathrm{f}$
Violante, I.M.P.; Sousa, I.M.; Venturini, C.I.; Ramalho, A.F.S.; Santos, R.A.N.; Ferrari, M. 2009. Avaliação in vitro da atividade fotoprotetora de extrato vegetais do cerrado de Mato Grosso. Revista Brasileira de Farmacognosia, 19(2):452-457.

Zatta, D.T.; Pimenta, F.C.P.; Tresvenzol, L.M.F.; Fiuza, T.S.; Bara, M.T.F.; Cunha, L.C.; Pucci, L.L.; Garrote, C.F.D.; Oliveira, F.N.M.; Paula, J.R. 2009. Estudo da atividade antibacteriana contra cepas de Pseudomonas aeruginosa e da Toxicidade aguda das folhas da Jacaranda decurrens. Latin American Journal of Pharmacy, 28(4):485-489. 